\title{
NADPH oxidase 2 (NOX2): a key target of oxidative stress-mediated platelet activation and thrombosis
}

Article

Accepted Version

Creative Commons: Attribution-Noncommercial-No Derivative Works 4.0

Fuentos, E., Gibbins, J. M., Holbrook, L. M. and Palomo, I. (2018) NADPH oxidase 2 (NOX2): a key target of oxidative stress-mediated platelet activation and thrombosis. Trends in Cardiovascular Medicine, 28 (7). pp. 429-434. ISSN 10501738 doi: https://doi.org/10.1016/j.tcm.2018.03.001 Available at https://centaur.reading.ac.uk/77489/

It is advisable to refer to the publisher's version if you intend to cite from the work. See Guidance on citing.

To link to this article DOI: http://dx.doi.org/10.1016/j.tcm.2018.03.001

Publisher: Elsevier

All outputs in CentAUR are protected by Intellectual Property Rights law, including copyright law. Copyright and IPR is retained by the creators or other copyright holders. Terms and conditions for use of this material are defined in the End User Agreement.

www.reading.ac.uk/centaur 
Central Archive at the University of Reading

Reading's research outputs online 
4

5

7

8 a Platelet Research Center, Department of Clinical Biochemistry and 9 Immunohaematology, Faculty of Health Sciences, Interdisciplinary Excellence 10 Research Program on Healthy Aging (PIEI-ES), Universidad de Talca, Talca, 11 Chile.

12 b Núcleo Científico Multidisciplinario, Universidad de Talca, Talca, Chile.

13 c Institute for Cardiovascular and Metabolic Research, School of Biological 14 Sciences, University of Reading, Reading, UK.

15

16

17 Eduardo Fuentes, edfuentes@utalca.cl

18 Jonathan Gibbins, j.m.gibbins@reading.ac.uk 


\section{ABSTRACT}

2 Oxidative stress represents an imbalance between the production of reactive 3 oxygen species (ROS) and the cellular antioxidant system. Increased levels of 4 oxidative stress contribute to the development of atherosclerosis that eventually 5 leads to thrombosis; a principle cause of heart attacks and strokes. Thrombosis is

6 a consequence of platelet activation and aggregate formation within the circulation.

7 Platelet ROS are mostly generated by reduced nicotinamide adenine dinucleotide

8 phosphate (NADPH) oxidase. NOX2 is an isoform from NADPH oxidase expressed

9 in platelets and an important regulator of platelet activation-associated thrombosis.

10 The present article aims to highlight the relative contribution of NOX2 as a key

11 target of different platelet activation pathways and antiplatelet treatment.

12

13 Keywords: platelet; antiplatelet; oxidative stress; NADPH oxidase; NOX2. 


\section{INTRODUCTION}

2 Cardiovascular diseases (CVD) continue to be a substantial health-care burden.

3 The recent decrease in cardiovascular mortality in high-income countries has been

4 associated with a rise in the numbers of aging patients living with CVD. Oxidative

5 stress is associated with several CVD, including hypertension, heart failure, stroke,

6 diabetes and atherosclerosis. The development of atherosclerosis in the arterial

7 circulation underlies the progress of thrombotic disease. Platelets are critical for

8 hemostasis, but under oxidative conditions, play also a key role in the process of

9 thrombosis (1).

10 Oxidative stress represents an imbalance between reactive oxygen species (ROS)

11 production and ROS removal by the cellular antioxidant defense system, whereby

12 they mediate damage to cell structures, including lipids, membranes, proteins and

13 DNA (2). Oxidative stress and ROS production have long been regarded as a key

14 pathophysiological mediator that ultimately leads to CVD. Chronic and acute

15 overproduction of ROS under pathophysiologic conditions is integral in the

16 development of CVD. In this context, ROS also participate in a wide variety of

17 pathophysiology processes such as elevated platelet activation (3).

18 Platelet activation is a complex process that involves different cellular signaling

19 pathways. Experimental and clinical studies support the pivotal role played by ROS

20 in elevated platelet activation. Collagen and thrombin-induced platelet aggregation

21 is associated with production of ROS, which acts as a second messenger by

22 stimulating the arachidonic acid metabolism and phospholipase C pathway (4-6). In 
1 addition, ROS plays a key role in agonists (collagen, thrombin, or calcium

2 ionophore [A23187])-induced glycoprotein (GP) lba ectodomain shedding (7).

3 Although ROS modulate signaling pathway during platelet adhesion and activation

4 does not individually activate GPIIb/IIla receptors (8).

5 In platelets, ROS are mostly generated by reduced nicotinamide adenine

6 dinucleotide phosphate (NADPH) oxidase; an enzyme complex that was primarily

7 described in phagocytes. NADPH oxidase of the NOX family are important

8 enzymatic sources of ROS (9). Seven isoforms of NOX have been described in

9 mammals and the NOX2 isoform is expressed in platelets, where it induces

10 superoxide anion $\left(\mathrm{O}_{2}{ }^{\circ}\right)$ production (10). The present article aims to highlight the

11 relative contribution of NOX2 as a key target of different platelet activation

12 pathways and antiplatelet treatment.

\section{OXIDATIVE STRESS AND PLATELET ACTIVATION}

14 Platelets have a dynamic functional repertoire with participation in hemostasis and

15 thrombosis, which is dependent on a complex balance of activatory and inhibitory

16 signaling pathways (11). Platelets play a key role in the prevention of excessive

17 blood loss through the formation of a thrombus. After vascular injury, platelets

18 rapidly adhere to activated endothelial cells and/or subendothelial matrix proteins

19 such as collagen and von Willebrand factor through receptor-ligand interactions.

20 Subsequently, activated platelets and the release of granular molecules such as

21 adenosine diphosphate (ADP), are essential for stable thrombus formation at the

22 site of vascular injury. However, excessive platelet activation and hyper-reactive 
1 platelets are thought to contribute to atherothrombosis that can lead to myocardial

2 infarction and stroke $(12,13)$.

3 Platelets are equipped with an effective enzymatic antioxidant system, the most

4 important of which are superoxide dismutase (SOD), catalase (CAT), glutathione

5 peroxidase (GPX), glutathione transferase (GST) and glutathione reductase

6 (GSSG-R). However, the imbalance between the formation of ROS and

7 antioxidative system efficiency contributes to the pathogenesis of thrombotic

8 disease, through elevated intracellular levels of ROS, which mediate elevated

9 platelet activation (14).

10 In platelets, ROS including superoxide anion, hydroxyl radicals or hydrogen

11 peroxide act as second messengers to modulate platelets via calcium mobilization,

12 nitric oxide (NO) inactivation and through the interaction with arachidonic acid to

13 enable the formation of isoprostanes. Notably, elevated levels of isoprostanes are

14 associated with systemic and local platelet activation $(15,16)$.

15 During activation, platelets generate ROS through several intracellular sources

16 such as NADPH oxidase, cyclooxygenases, uncoupled endothelial nitric oxide

17 synthase (eNOS), xanthine oxidase (XO) and mitochondrial respiration (6, 17-19).

18 However, data concerning expression eNOS by platelets remain controversial.

19 Gambaryan et al., demonstrate that human and mouse platelets do not

20 contain eNOS proteins or mRNA (20).

21 NADPH OXIDASE AND PLATELET ACTIVATION 
1 Recently, it has become evident that NADPH oxidase activity is functionally

2 expressed not only in phagocytes but also in various cell types, including platelets.

3 Platelet NADPH oxidase is a multicomponent protein complex assembled by the

4 cellular subunits $\mathrm{p} 47^{\text {phox }}, \mathrm{p} 67^{\text {phox }}$, and the membrane-bound proteins $\mathrm{p} 22^{\text {phox }}$ and

5 gp91 phox, which together with the small GTPase Rac1/2 associate to form the

6 active enzyme complex (21).

7 Platelet-associated NADPH oxidase mediates a thrombogenic phenotype. Growing

8 data from experimental and clinical studies provide evidence that NADPH oxidase

9 is implicated in altered platelet activation via superoxide anion production $(22,23)$.

10 Collagen activation induces NADPH oxidase-dependent superoxide anion release

11 in platelets, which in turn enhances the availability of released ADP, resulting in

12 increased thrombus formation (24). Indeed, NADPH oxidase inhibitors have been

13 shown to reduce platelet aggregation and thrombus formation on collagen under

14 high shear $(25,26)$. Meanwhile, inhibition with apocynin (NOX2 inhibitor that

15 prevents serine phosphorylation of $\mathrm{p} 47^{\text {phox }}$ and blocks its association with $\mathrm{gp} 91^{\text {phox }}$ )

16 reduces platelet adhesion in patients with advanced atherosclerosis (27).

17 Seven distinct members of the NADPH oxidase family have been characterized, of

18 which four (namely NOX1, 2, 4 and 5) may have cardiovascular functions (28).

19 Among the enzymes generating ROS, NOX1 and NOX2 play differential roles in

20 different platelet activation pathways. Thus, using knockout mice, NOX1(-/Y)

21 platelets showed selective defects in thrombin- or thromboxane A2 analog

22 U46619-mediated platelet activation. 


\section{NOX2 AND PLATELET ACTIVATION}

2 NOX2 has been implicated in various aspects of CVD. It is suggested to play a role

3 in favouring the occurrence of atrial fibrillation (AF) after cardiac surgery via

4 formation of ROS, and in peripheral artery disease patients, ROS generated by

5 NOX2 contribute to reduce flow-mediated dilation $(29,30)$. In addition, NOX2

6 promotes carotid plaque rupture and stroke occurrence (31). Meanwhile,

7 administration of an antioxidant (propionyl-L-carnitine) is able to improve arterial

8 dilatation via NOX2 inhibition (32).

9 Platelet-leukocyte interactions on activated endothelial cells play an important role

10 during microvascular occlusion under oxidative stress conditions. Platelet NOX2-

11 produced ROS regulated P-selectin exposure upon agonist stimulation and the

12 ligand-binding function of GPlba, which contribute to the pathology of hepatic

13 ischemia/reperfusion injury during vascular inflammation (33). Furthermore the

14 activation of NOX2 on platelets is increased in heart failure, likely as a

15 consequence of the underlying inflammatory processes (34).

16 NOX2 is expressed in platelets and the megakaryocyte cell-line (MEG01). In

17 human platelets the enzymatic activity of NOX2 believed to be an important source

18 of ROS in platelets $(10,21,35)$. NOX2-generated superoxide anion is rapidly

19 converted into the longer-lasting and membrane diffusible hydrogen peroxide,

20 which is the major ROS contributing to pathological signaling through oxidative

21 modification of lipids and proteins $(24,36)$. This is evidenced by the almost absent

22 ROS production by platelets from patients with hereditary deficiency of NOX2 (37, 
1 38). The platelet NOX2 enzyme consists of membrane subunits ( $p 22^{\text {phox }}$ and

2 gp91 phox $)$ and cytosolic components ( $\mathrm{p} 47^{\text {phox }}, \mathrm{p} 67^{\text {phox }}$ and $\mathrm{p} 40^{\text {phox }}$ ), which together

3 with the small GTPase rac1/2 associate to form the active enzyme complex (Figure

4 1) $(21,36,39)$. Upon activation, binding of Rac1 GTPase to p67phox plays a

5 critical role in NOX2 activation by facilitating the assembly of the NOX2 enzyme

6 complex. Meanwhile, inhibition of Rac1 GTPase by NSC23766 or gene targeting

7 on Rac1 GTPase clearly demonstrated that Rac1 is essential for agonist induced

8 ROS generation in platelets $(40,41)$. Therefore, NOX2 could be a key target of

9 different platelet activation pathways. The pathways modulated by platelet NOX2

10 are illustrated in Figure 1.

\section{1 a) Activation pathways of platelet NOX2}

12 NOX2 can be activated by sCD40L/CD40L, collagen/GPVI or ox-LDL/CD36.

13 SCD40L/CD40L. CD40 ligand (CD40L) is expressed and functional on platelets, 14 and plays a pivotal role in atherosclerosis (42). CD40L is cryptic in unstimulated 15 platelets but is rapidly unveiled on the platelet surface after platelet stimulation 16 (43). Platelet production of superoxide anion plays a key role in CD40L expression 17 and platelets from patients with an inherited deficiency of gp91 phox exhibited 18 defects in superoxide anion production and CD40L expression (36). In addition, 19 such patients exhibit very low levels of SCD40L in unstimulated platelets and no 20 changes following platelet stimulation (36). This suggests that the surface21 expressed CD40L is subsequently cleaved over a period of minutes to hours, 22 generating a soluble fragment termed SCD40L that remains trimeric. Indeed, it has 
1 been calculated that $>95 \%$ of circulating SCD40L originates from platelets (43).

2 Elevated levels of SCD40L enhance platelet activation, aggregation, and platelet-

3 leukocyte conjugation, and increase stimulation-induced platelet increase of ROS

4 through activation of Akt and p38 MAP kinase signaling pathways (44). In this

5 context, NOX2 is an important mediator in SCD40L-induced ROS generation.

6 Consistent with this, apocynin inhibits the increase of ROS induced by SCD40L

7 (44). Moreover, plasma levels of SCD40L are dependent on the expression of

8 NOX2. Additionally $\mathrm{sCD} 40 \mathrm{~L}$ is reduced in gp9 $1^{\text {phox }}$ defective patients and is

9 expressed at higher levels in obese women where NOX2 is upregulated (45).

10 Collagen/GPVI. GPVI is a membrane glycoprotein unique to platelets and has

11 been identified as a physiological receptor for collagen (46). NOX2 subunit p47phox

12 and binding partner tumor necrosis factor receptor associated factor (TRAF) 4 are

13 associated with the cytoplasmic tails of GPVI, and link ROS production to NOX2

14 function (47). TRAF4 is immediately upstream of a proline-rich sequence that

15 binds the tyrosine kinase Lyn. Lyn is involved in phosphorylation of the 16 immunoreceptor tyrosine-based activation motif (ITAM) motif within the Fc receptor

17 (FcR) $\gamma$-chain (in complex with GPVI), leading to activation of Syk and the Syk18 dependent signaling pathway involving SLP76, Bruton's tyrosine kinase (BTK),

19 phosphatidylinositol 3-kinase (PI3K), phospholipase C (PLC) and protein kinase C 20 (PKC). GPVI stimulation culminates in affinity up-regulation of GPIlb/llla allowing

21 fibrinogen binding and thus, platelet aggregation and thrombus formation (47).

22 NOX2 (-/-) platelets showed reduced ROS generation and potent inhibition of CRP- 
1 induced platelet activation. Also, a partial inhibition of thrombin-

2 induced platelet activation was observed (22).

3 ox-LDL/CD36. Oxidized lipids are markers of oxidative stress, important mediators

4 of atherosclerosis and activators of platelets. Metabolic syndrome in obese

5 patients, diabetic or non-diabetic, is associated with increased oxidative stress in

6 low-density lipoprotein (ox-LDL), which triggers platelet activation (48, 49). In

7 addition, a low HDL phenotype, both in CVD patients and healthy subjects, is

8 associated with increase of lipid peroxidation and platelet activation (50).

9 A number of studies have suggested that ox-LDL may bind to and activate platelets

10 (51-53). Platelet CD36, a member of the Type 2 scavenger receptor family, is a

11 multiligand pattern recognition receptor that recognizes specific oxidized

12 phospholipids, molecules expressed on microbial pathogens, apoptotic cells, and

13 cell-derived microparticles. Elevated platelet CD36 expression may contribute to

14 increased risk of thrombo-embolism. The interactions of platelet CD36 with

15 endogenous oxidized lipids play a crucial role in the prothrombotic phenotype (54).

16 CD36 binds ox-LDL and induces platelet hyperactivity via generation of ROS. The

17 synthesis of ROS by ox-LDL/CD36 required Src-family kinases, PKC-dependent 18 phosphorylation and activation of NOX2, which is blocked by CD36 inhibitors,

19 NOX2 inhibitor (gp91ds-tat) and is absent in NOX2(-/-) mice (51). Therefore 20 platelet activation via specific ox-LDL/CD36 is mediated by NOX2 activation (55).

21 Moreover, at pathophysiological levels in hyperlipidemic patients, oxidized choline 
1 glycerophospholipids are able to bind and promoted platelet activation via CD36 2 (54).

3 b) Downstream signaling pathway of platelet NOX2 activation

4 Downstream of NOX2, ROS production occurs, thromboxane A2 levels are

5 increased and P-selectin expression and intracellular $\mathrm{Ca}^{2+}$ release occur.

6 Intracellular $\mathrm{Ca}^{2+}$ release modulates an early stage of cell activation such as

7 granular secretion. In addition, platelet NOX2-derived ROS, have been shown to

8 mediate the oxidation of sulfhydryl groups in GPIba and enhance its ligand-binding

9 function with von Willebrand factor on endothelial cells and the integrin $\alpha M \beta 2$ on

10 monocytes $(33,56)$.

11 The 8-iso-prostaglandin F2 alpha (8-iso-PGF2 $\alpha$ ) is a stable isoprostane and

12 reliable marker of oxidative stress in vivo (57). Elevated levels of 8-iso-PGF2 $\alpha$ in

13 CVD are associated with systemic and local platelet activation and notably, platelet

14 NOX2 contributes to the formation of 8 -iso-PGF2 $\alpha(45,58)$. In children with

15 hypercholesterolemia, platelet $\mathrm{gp} 91^{\text {phox }}$ and urinary isoprostanes levels are

16 increased (38). Platelet 8-iso-PGF2 $\alpha$ formed as a consequence of NOX2 activation

17 contributes to platelet recruitment via activation of GPIIb/IIla (39).

18 CLINICAL SIGNIFICANCE OF PLATELET NADPH

19 Excessive ROS production by NADPH oxidase causes cellular stress, leading to 20 various diseases, including thrombotic conditions. Therefore, a complete 21 understanding of the function of platelet-derived NADPH oxidase is important to 22 direct the role of this enzyme towards antiplatelet therapy. 
1 Patients with the clinical syndrome of chronic granulomatous disease (CGD) have

2 increased propensity to infection with certain bacteria. Importantly, investigation of

3 X-linked CGD patients have provided a clinical model to study the role of NADPH

4 in the atherothrombosis and its clinical sequelae. In this context, CGD patients with

5 gp9 $91^{\text {phox }}$ or p4 $7^{\text {phox }}$ deficiency have an impaired inactivation of NO would result in

6 enhanced NO bioavailability and arterial dilatation. In addition, these patients had

7 significant reduction of carotid intima-media thickness with a similar reduction

8 detected in both p47 $7^{\text {phox_ }}$ and gp91 ${ }^{\text {phox }}$-deficient subtypes. In contrast, the

9 prevalence of coronary arterial calcification was similar between patients with CGD

10 and controls. These finding suggests that loss of NADPH function prevents or

11 retards atherosclerosis progression even in a disease such as CGD (59).

12 Platelets from NOX2(-/-) patients displayed defective arterial thrombosis but

13 bleeding time was not affected in CGD patients, suggesting an important role for

14 platelet NOX2 in thrombosis but not in hemostasis $(22,55)$. Thus platelet

15 aggregation of platelets obtained from CGD patients was significantly reduced in

16 association with impairment of 8 -iso-PGF2 $\alpha$ production. In addition, NOX2(-/-)

17 platelets showed potent inhibition of collagen-related peptide (CRP, a GPVI 18 selective agonist)-induced platelet activation, and also showed partial inhibition of

19 thrombin-induced platelet activation. Consistent with these findings, platelets from

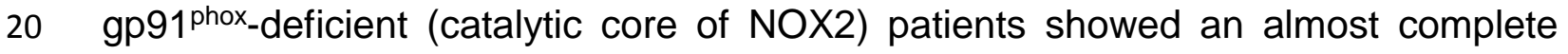
21 absence of superoxide anion and CD40L expression, but collagen-induced platelet 22 aggregation was similar to that of healthy subjects (36). 
1 ROS formed by NOX activity play a critical role in CVD, indeed, the C242T

2 polymorphism of the NOX gene is a pathogenetic risk factor for CVD (60).

3 Tamoxifen is effective in the prevention and treatment of breast cancer, but its use

4 is associated with an increased risk of thrombosis. Incubation of platelets with the

5 active metabolites of tamoxifen increases stimulation-dependent superoxide

6 anion release through a NADPH oxidase-dependent mechanism and therefore

7 may cause thrombosis (61).

8 Up to one-third of serious vascular events in high-risk patients are attributable to 9 aspirin resistance. In platelets from aspirin-resistant patients, both NADPH-driven 10 superoxide anion production, and expression of gp9 $1^{\text {phox }}$ and $p 67^{\text {phox }}$ subunits 11 tended to increase. Maximal aggregation of aspirin resistant platelets to collagen

12 and epinephrine was significantly decreased by NADPH oxidase inhibitors 13 (diphenylene iodonium and apocynin), whereas they had no effect in aspirin 14 sensitive platelets. These data suggest a potential use of NADPH oxidase 15 inhibitors in the occurrence of thrombosis in high-risk cardiac patients $(56,62)$.

16 Since NOX2 is expressed in tissues throughout the cardiovascular system, and 17 plays an important role in platelet activation in thrombosis but not hemostasis, 18 platelet NOX2 inhibition might represent a promising strategy to prevent 19 thrombosis in both aspirin resistant and tamoxifen treated patients $(22,34,63)$. As 20 shown in Table 1, platelet NOX2 inhibitors could be used in the prevention of CVD 21 via inhibition of platelet activation. The main mechanisms inhibitors of NOX2 are 22 compounds which bind to $\mathrm{p} 67^{\text {phox }}, \mathrm{p} 47^{\text {phox }}$ or Rac1; thereby preventing assembly of 
1 the active NOX2 complex (64-69). These findings may provide a rationale for the

2 use of perhexiline and statins to prevent platelet activation via inhibition of NOX2.

3 CONCLUSION

4 There is abundant evidence that oxidative stress, caused by an excess of ROS,

5 regulates several components of thrombosis, including platelet activation. NOX2 is

6 an isoform from NADPH oxidase expressed in platelets and is likely one of the

7 important sources of oxidative stress. Platelet NOX2 is a key target of different

8 platelet activation pathways, and may represent an alternative or additional

9 therapeutic target to prevent thrombosis associated with oxidative stress.

10 Practice Points:

11 NOX2 plays a prominent role in platelet activation.

12 NOX2 can be activated by sCD40L/CD40L, collagen/GPVI or ox-LDL/CD36.

13 Perhexiline (an approved prescription drug for angina) and statins (atorvastatin and

14 rosuvastatin) used clinically present inhibition of NOX2 and antiplatelet activity

15 Research Agenda:

16 Clinical value of platelet NOX2 inhibitors.

17 Experimental studies on side effects of platelet NOX2 inhibitors.

18 Conflict of interest

19 The authors have no conflicts of interest to disclose.

20 Acknowledgements 
Eduardo Fuentes thanks FONDECYT (FONDECYT Initiation $N^{\circ} 11140142$ ). This work was also funded by Interdisciplinary Excellence Research Program on Healthy Aging (PIEI-ES).

\section{REFERENCES}

1. Chatterjee M, Rath D, Schlotterbeck J, Rheinlaender J, Walker-Allgaier B, Alnaggar N, et al. Regulation of oxidized platelet lipidome: implications for coronary artery disease. Eur Heart J. 2017 Apr 18.

2. Sugamura K, Keaney JF, Jr. Reactive oxygen species in cardiovascular disease. Free Radic Biol Med. 2011 Sep 01;51(5):978-92.

3. Morel A, Bijak M, Miller E, Rywaniak J, Miller S, Saluk J. Relationship between the Increased Haemostatic Properties of Blood Platelets and Oxidative Stress Level in Multiple Sclerosis Patients with the Secondary Progressive Stage. Oxid Med Cell Longev. 2015;2015:240918.

4. Pignatelli P, Pulcinelli FM, Lenti L, Gazzaniga PP, Violi F. Hydrogen peroxide is involved in collagen-induced platelet activation. Blood. 1998 Jan 15;91(2):484-90.

5. Caccese D, Pratico D, Ghiselli A, Natoli S, Pignatelli P, Sanguigni V, et al. Superoxide anion and hydroxyl radical release by collagen-induced platelet aggregation--role of arachidonic acid metabolism. Thromb Haemost. 2000 Mar;83(3):485-90.

6. Wachowicz B, Olas B, Zbikowska HM, Buczynski A. Generation of reactive oxygen species in blood platelets. Platelets. 2002 May;13(3):175-82.

7. Zhang $\mathrm{P}$, Du J, Zhao L, Wang $X$, Zhang $Y$, Yan $R$, et al. The role of intraplatelet reactive oxygen species in the regulation of platelet glycoprotein Ibalpha ectodomain shedding. Thromb Res. 2013;132(6):696-701.

8. Sill JC, Proper JA, Johnson ME, Uhl CB, Katusic ZS. Reactive oxygen species and human platelet GP Ilb/llla receptor activation. Platelets. 2007 Dec;18(8):613-9.

9. Brandes RP, Weissmann N, Schroder K. Nox family NADPH oxidases: Molecular mechanisms of activation. Free Radic Biol Med. 2014 Nov;76:208-26.

10. Walsh TG, Berndt MC, Carrim N, Cowman J, Kenny D, Metharom P. The role of Nox1 and Nox2 in GPVI-dependent platelet activation and thrombus formation. Redox Biol. 2014;2:178-86.

11. Bye AP, Unsworth AJ, Gibbins JM. Platelet signaling: a complex interplay between inhibitory and activatory networks. J Thromb Haemost. 2016 May;14(5):918-30.

12. Unsworth AJ, Bye AP, Tannetta DS, Desborough MJR, Kriek N, Sage T, et al. Farnesoid $X$ Receptor and Liver $X$ Receptor Ligands Initiate Formation of Coated Platelets. Arterioscler Thromb Vasc Biol. 2017 Aug;37(8):1482-93. 
13. Jones $\mathrm{Cl}$, Tucker $\mathrm{KL}$, Sasikumar $\mathrm{P}$, Sage $\mathrm{T}$, Kaiser WJ, Moore $\mathrm{C}$, et al. Integrin-linked kinase regulates the rate of platelet activation and is essential for the formation of stable thrombi. J Thromb Haemost. 2014 Aug;12(8):1342-52.

14. Jang JY, Wang SB, Min JH, Chae YH, Baek JY, Yu DY, et al. Peroxiredoxin II is an antioxidant enzyme that negatively regulates collagen-stimulated platelet function. J Biol Chem. 2015 May 1;290(18):11432-42.

15. Pastori D, Pignatelli P, Carnevale R, Violi F. Nox-2 up-regulation and platelet activation: Novel insights. Prostaglandins Other Lipid Mediat. 2015 Jul;120:50-5.

16. Dayal S, Wilson KM, Motto DG, Miller FJ, Jr., Chauhan AK, Lentz SR. Hydrogen peroxide promotes aging-related platelet hyperactivation and thrombosis. Circulation. 2013 Mar 26;127(12):1308-16.

17. Wang Z, Cai F, Chen X, Luo M, Hu L, Lu Y. The role of mitochondriaderived reactive oxygen species in hyperthermia-induced platelet apoptosis. PLoS One. 2013;8(9):e75044.

18. Iuliano L, Colavita AR, Leo R, Pratico D, Violi F. Oxygen free radicals and platelet activation. Free Radic Biol Med. 1997;22(6):999-1006.

19. Stepniewska J, Dolegowska B, Cecerska-Heryc E, Golembiewska E, Malinowska-Jedraszczyk A, Marchelek-Mysliwiec $M$, et al. The activity of antioxidant enzymes in blood platelets in different types of renal replacement therapy: a cross-sectional study. Int Urol Nephrol. 2016 Apr;48(4):593-9.

20. Gambaryan S, Kobsar A, Hartmann S, Birschmann I, Kuhlencordt PJ, Muller-Esterl W, et al. NO-synthase-/NO-independent regulation of human and murine platelet soluble guanylyl cyclase activity. J Thromb Haemost. 2008 Aug;6(8):1376-84.

21. Seno T, Inoue N, Gao D, Okuda M, Sumi $Y$, Matsui $K$, et al. Involvement of $\mathrm{NADH} / \mathrm{NADPH}$ oxidase in human platelet ROS production. Thromb Res. $2001 \mathrm{Sep}$ 1;103(5):399-409.

22. Delaney MK, Kim K, Estevez B, Xu Z, Stojanovic-Terpo A, Shen B, et al. Differential Roles of the NADPH-Oxidase 1 and 2 in Platelet Activation and Thrombosis. Arterioscler Thromb Vasc Biol. 2016 May;36(5):846-54.

23. Iuliano L, Pratico D, Ghiselli A, Bonavita MS, Violi F. Superoxide dismutase triggers activation of "primed" platelets. Arch Biochem Biophys. 1991 Aug 15;289(1):180-3.

24. Krotz F, Sohn HY, Gloe T, Zahler S, Riexinger T, Schiele TM, et al. $\mathrm{NAD}(\mathrm{P}) \mathrm{H}$ oxidase-dependent platelet superoxide anion release increases platelet recruitment. Blood. 2002 Aug 1;100(3):917-24.

25. Begonja AJ, Gambaryan S, Geiger J, Aktas B, Pozgajova M, Nieswandt B, et al. Platelet $\mathrm{NAD}(\mathrm{P}) \mathrm{H}$-oxidase-generated $\mathrm{ROS}$ production regulates alphallbbeta3-integrin activation independent of the NO/cGMP pathway. Blood. 2005 Oct 15;106(8):2757-60.

26. Begonja AJ, Teichmann L, Geiger J, Gambaryan S, Walter U. Platelet regulation by NO/cGMP signaling and $\mathrm{NAD}(\mathrm{P}) \mathrm{H}$ oxidase-generated ROS. Blood Cells Mol Dis. 2006 Mar-Apr;36(2):166-70. 
27. Liu Y, Davidson BP, Yue Q, Belcik T, Xie A, Inaba Y, et al. Molecular imaging of inflammation and platelet adhesion in advanced atherosclerosis effects of antioxidant therapy with NADPH oxidase inhibition. Circ Cardiovasc Imaging. 2013 Jan 1;6(1):74-82.

28. Sirker A, Zhang M, Shah AM. NADPH oxidases in cardiovascular disease: insights from in vivo models and clinical studies. Basic Res Cardiol. 2011 Sep;106(5):735-47.

29. Cangemi R, Celestini A, Calvieri C, Carnevale R, Pastori D, Nocella C, et al. Different behaviour of NOX2 activation in patients with paroxysmal/persistent or permanent atrial fibrillation. Heart. 2012 Jul;98(14):1063-6.

30. Violi F, Carnevale R, Calvieri C, Nocella C, Falcone M, Farcomeni A, et al. Nox2 up-regulation is associated with an enhanced risk of atrial fibrillation in patients with pneumonia. Thorax. 2015 Oct;70(10):961-6.

31. Carbone F, Teixeira PC, Braunersreuther V, Mach F, Vuilleumier N, Montecucco F. Pathophysiology and Treatments of Oxidative Injury in Ischemic Stroke: Focus on the Phagocytic NADPH Oxidase 2. Antioxid Redox Signal. 2015 Aug 10;23(5):460-89.

32. Loffredo L, Carnevale R, Cangemi R, Angelico F, Augelletti T, Di Santo S, et al. NOX2 up-regulation is associated with artery dysfunction in patients with peripheral artery disease. Int J Cardiol. 2013 Apr 30;165(1):184-92.

33. Kim K, Li J, Tseng A, Andrews RK, Cho J. NOX2 is critical for heterotypic neutrophil-platelet interactions during vascular inflammation. Blood. 2015 Oct 15;126(16):1952-64.

34. Cangemi R, Celestini A, Del Ben M, Pignatelli P, Carnevale R, Proietti M, et al. Role of platelets in NOX2 activation mediated by TNFalpha in heart failure. Intern Emerg Med. 2014 Mar;9(2):179-85.

35. Chlopicki S, Olszanecki R, Janiszewski M, Laurindo FR, Panz T, Miedzobrodzki J. Functional role of NADPH oxidase in activation of platelets. Antioxid Redox Signal. 2004 Aug;6(4):691-8.

36. Pignatelli $P$, Sanguigni V, Lenti L, Ferro D, Finocchi A, Rossi $P$, et al. gp91phox-dependent expression of platelet CD40 ligand. Circulation. 2004 Sep 7;110(10):1326-9.

37. Violi F, Pignatelli P. Platelet NOX, a novel target for anti-thrombotic treatment. Thromb Haemost. 2014 May 5;111(5):817-23.

38. Martino F, Loffredo L, Carnevale R, Sanguigni V, Martino E, Catasca E, et al. Oxidative stress is associated with arterial dysfunction and enhanced intimamedia thickness in children with hypercholesterolemia: the potential role of nicotinamide-adenine dinucleotide phosphate oxidase. Pediatrics. 2008 Sep;122(3):e648-55.

39. Pignatelli P, Carnevale R, Di Santo S, Bartimoccia S, Sanguigni V, Lenti L, et al. Inherited human gp91phox deficiency is associated with impaired isoprostane formation and platelet dysfunction. Arterioscler Thromb Vasc Biol. 2011 Feb;31(2):423-34. 
40. Akbar H, Duan X, Saleem S, Davis AK, Zheng Y. RhoA and Rac1 GTPases Differentially Regulate Agonist-Receptor Mediated Reactive Oxygen Species Generation in Platelets. PLoS One. 2016;11(9):e0163227.

41. Dutting S, Heidenreich J, Cherpokova D, Amin E, Zhang SC, Ahmadian MR, et al. Critical off-target effects of the widely used Rac1 inhibitors NSC23766 and EHT1864 in mouse platelets. J Thromb Haemost. 2015 May;13(5):827-38.

42. Lievens D, Zernecke A, Seijkens T, Soehnlein O, Beckers L, Munnix IC, et al. Platelet CD40L mediates thrombotic and inflammatory processes in atherosclerosis. Blood. 2010 Nov 18;116(20):4317-27.

43. Andre P, Nannizzi-Alaimo L, Prasad SK, Phillips DR. Platelet-derived CD40L: the switch-hitting player of cardiovascular disease. Circulation. 2002 Aug 20;106(8):896-9.

44. Chakrabarti S, Varghese S, Vitseva O, Tanriverdi K, Freedman JE. CD40 ligand influences platelet release of reactive oxygen intermediates. Arterioscler Thromb Vasc Biol. 2005 Nov;25(11):2428-34.

45. Carnevale R, Loffredo L, Sanguigni V, Plebani A, Rossi P, Pignata C, et al. Different degrees of NADPH oxidase 2 regulation and in vivo platelet activation: lesson from chronic granulomatous disease. J Am Heart Assoc. 2014 Jun;3(3):e000920.

46. Nieswandt B, Watson SP. Platelet-collagen interaction: is GPVI the central receptor? Blood. 2003 Jul 15;102(2):449-61.

47. Arthur JF, Qiao J, Shen Y, Davis AK, Dunne E, Berndt MC, et al. ITAM receptor-mediated generation of reactive oxygen species in human platelets occurs via Syk-dependent and Syk-independent pathways. J Thromb Haemost. 2012 Jun;10(6):1133-41.

48. Colas R, Sassolas A, Guichardant M, Cugnet-Anceau C, Moret M, Moulin P, et al. LDL from obese patients with the metabolic syndrome show increased lipid peroxidation and activate platelets. Diabetologia. 2011 Nov;54(11):2931-40.

49. Davi G, Guagnano MT, Ciabattoni G, Basili S, Falco A, Marinopiccoli M, et al. Platelet activation in obese women: role of inflammation and oxidant stress. JAMA. 2002 Oct 23-30;288(16):2008-14.

50. Vazzana N, Ganci A, Cefalu AB, Lattanzio S, Noto D, Santoro N, et al. Enhanced lipid peroxidation and platelet activation as potential contributors to increased cardiovascular risk in the low-HDL phenotype. J Am Heart Assoc. 2013 Apr;2(2):e000063.

51. Magwenzi S, Woodward C, Wraith KS, Aburima A, Raslan Z, Jones H, et al. Oxidized LDL activates blood platelets through CD36/NOX2-mediated inhibition of the cGMP/protein kinase G signaling cascade. Blood. 2015 Apr 23;125(17):2693703.

52. Wraith KS, Magwenzi S, Aburima A, Wen Y, Leake D, Naseem KM. Oxidized low-density lipoproteins induce rapid platelet activation and shape change through tyrosine kinase and Rho kinase-signaling pathways. Blood. $2013 \mathrm{Jul}$ 25;122(4):580-9. 
53. Korporaal SJ, Van Eck M, Adelmeijer J, ljsseldijk M, Out R, Lisman T, et al. Platelet activation by oxidized low density lipoprotein is mediated by CD36 and scavenger receptor-A. Arterioscler Thromb Vasc Biol. 2007 Nov;27(11):2476-83. 54. Podrez EA, Byzova TV, Febbraio M, Salomon RG, Ma Y, Valiyaveettil M, et al. Platelet CD36 links hyperlipidemia, oxidant stress and a prothrombotic phenotype. Nat Med. 2007 Sep;13(9):1086-95.

55. Carnevale R, Bartimoccia S, Nocella C, Di Santo S, Loffredo L, Illuminati G, et al. LDL oxidation by platelets propagates platelet activation via an oxidative stress-mediated mechanism. Atherosclerosis. 2014 Nov;237(1):108-16.

56. Basili S, Pignatelli P, Tanzilli G, Mangieri E, Carnevale R, Nocella C, et al. Anoxia-reoxygenation enhances platelet thromboxane $\mathrm{A} 2$ production via reactive oxygen species-generated NOX2: effect in patients undergoing elective percutaneous coronary intervention. Arterioscler Thromb Vasc Biol. 2011 Aug;31(8):1766-71.

57. Davi G, Chiarelli F, Santilli F, Pomilio M, Vigneri S, Falco A, et al. Enhanced lipid peroxidation and platelet activation in the early phase of type 1 diabetes mellitus: role of interleukin-6 and disease duration. Circulation. 2003 Jul 1;107(25):3199-203.

58. Carnevale R, luliano L, Nocella C, Bartimoccia S, Trape S, Russo R, et al. Relationship between platelet and urinary 8-Iso-PGF2alpha levels in subjects with different degrees of NOX2 regulation. J Am Heart Assoc. 2013 Jun;2(3):e000198.

59. Violi F, Carnevale R, Loffredo L, Pignatelli P, Gallin JI. NADPH Oxidase-2 and Atherothrombosis: Insight From Chronic Granulomatous Disease. Arterioscler Thromb Vasc Biol. 2017 Feb;37(2):218-25.

60. Ito D, Murata M, Watanabe K, Yoshida T, Saito I, Tanahashi N, et al. C242T polymorphism of NADPH oxidase p22 PHOX gene and ischemic cerebrovascular disease in the Japanese population. Stroke. 2000 Apr;31(4):936-9.

61. Vitseva O, Flockhart DA, Jin Y, Varghese S, Freedman JE. The effects of tamoxifen and its metabolites on platelet function and release of reactive oxygen intermediates. J Pharmacol Exp Ther. 2005 Mar;312(3):1144-50.

62. Stef G, Csiszar A, Ziangmin Z, Ferdinandy P, Ungvari Z, Veress G. Inhibition of $\mathrm{NAD}(\mathrm{P}) \mathrm{H}$ oxidase attenuates aggregation of platelets from high-risk cardiac patients with aspirin resistance. Pharmacol Rep. 2007 Jul-Aug;59(4):42836.

63. Lassegue B, San Martin A, Griendling KK. Biochemistry, physiology, and pathophysiology of NADPH oxidases in the cardiovascular system. Circ Res. 2012 May 11;110(10):1364-90.

64. Bosco EE, Kumar S, Marchioni F, Biesiada J, Kordos M, Szczur K, et al. Rational design of small molecule inhibitors targeting the Rac GTPase-p67(phox) signaling axis in inflammation. Chem Biol. 2012 Feb 24;19(2):228-42.

65. Jaquet V, Marcoux J, Forest E, Leidal KG, McCormick S, Westermaier Y, et al. NADPH oxidase (NOX) isoforms are inhibited by celastrol with a dual mode of action. Br J Pharmacol. 2011 Sep;164(2b):507-20. 
1 66. Smith SM, Min J, Ganesh T, Diebold B, Kawahara T, Zhu Y, et al. Ebselen 2 and congeners inhibit NADPH oxidase 2-dependent superoxide generation by 3 interrupting the binding of regulatory subunits. Chem Biol. 2012 Jun 22;19(6):752463.

5 67. Altenhofer S, Radermacher KA, Kleikers PW, Wingler K, Schmidt HH. 6 Evolution of NADPH Oxidase Inhibitors: Selectivity and Mechanisms for Target 7 Engagement. Antioxid Redox Signal. 2015 Aug 10;23(5):406-27.

8 68. Dwivedi S, Pandey D, Khandoga AL, Brandl R, Siess W. Rac1-mediated 9 signaling plays a central role in secretion-dependent platelet aggregation in human blood stimulated by atherosclerotic plaque. J Transl Med. 2010 Dec 06;8:128.

69. Akbar H, Kim J, Funk K, Cancelas JA, Shang X, Chen L, et al. Genetic and pharmacologic evidence that Rac1 GTPase is involved in regulation of platelet secretion and aggregation. J Thromb Haemost. 2007 Aug;5(8):1747-55.

(1)

(1)

17

8

9

0

1

2

3

4

5

6

7

8

9

0

1


1 Table 1. Inhibitors of platelet NOX2 with antiplatelet activity.

\begin{tabular}{|c|c|c|}
\hline Drugs & $\begin{array}{l}\text { NOX2 } \\
\text { inhibition }\end{array}$ & Antiplatelet activity \\
\hline Phox-l1 & $\begin{array}{l}\text { Phox- } 11 \text { binds to } p 67^{\text {phox }} \text { and } \\
\text { abrogates Rac1 binding. }\end{array}$ & $\begin{array}{l}\text { Platelets treated with Phox-I inhibited CRP, } \\
\text { thrombin or U46619 induced ROS generation, P- } \\
\text { selectin expression, ATP secretion and } \\
\text { aggregation. }\end{array}$ \\
\hline Celastrol & $\begin{array}{l}\text { Celastrol bound to } \mathrm{SH} 3 \\
\text { domain of p47 phox and } \\
\text { disrupted the binding of the } \\
\text { proline rich region of } \mathrm{p} 22^{\text {phox }}\end{array}$ & $\begin{array}{l}\text { Celastrol inhibited ADP or thrombin-induced } \\
\text { expression of P-selectin and GPIll/Illa, and ADP- } \\
\text { stimulated platelet fibrinogen binding. }\end{array}$ \\
\hline Ebselen & $\begin{array}{l}\text { Ebselen interrupted the } \\
\text { translocation of p47phox to } \\
\text { membranes. }\end{array}$ & $\begin{array}{l}\text { In aspirin-treated human platelets ebselen } \\
\text { inhibited agonist-triggered increase in intracellular } \\
\text { calcium. }\end{array}$ \\
\hline NOX2ds-tat & $\begin{array}{l}\text { NOX2ds-tat binds to p } 47^{\text {phox }} \text {, } \\
\text { thereby preventing assembly } \\
\text { of the active NOX } 2 \text { complex. }\end{array}$ & $\begin{array}{l}\text { NOX2ds-tat inhibited platelet oxidative stress and } \\
\text { function including platelet ROS, NOX2 activation, } \\
\text { 8-iso-PGF2 } \alpha \text { formation and platelet recruitment. }\end{array}$ \\
\hline Suramin & $\begin{array}{l}\text { Inhibited biochemical NOX2 } \\
\text { activity. }\end{array}$ & $\begin{array}{l}\text { Suramin inhibited platelet aggregation induced by } \\
\text { thrombin, PAF, ALPA, or arachidonic acid } \\
\text { and increase in intracellular calcium. }\end{array}$ \\
\hline Perhexiline & $\begin{array}{l}\text { Inhibited biochemical NOX2 } \\
\text { activity. }\end{array}$ & $\begin{array}{l}\text { Perhexiline increase NO/cGMP in SAP and ACS } \\
\text { patients. }\end{array}$ \\
\hline $\begin{array}{l}\text { Statins } \\
\text { (atorvastatin } \\
\text { and } \\
\text { rosuvastatin ) }\end{array}$ & $\begin{array}{l}\text { Reduce the expression of } \\
\text { Rac1, p22 }\end{array}$ & $\begin{array}{l}\text { Inhibited platelet activation and isoprostanes, } \\
\text { TXA2 and platelet } \mathrm{O}_{2}{ }^{*-} \text { release. }\end{array}$ \\
\hline 2 ACS: & te coronary syndromes, ADP: adenosine d & hosphate, ALPA: alkyllysophosphatidic acid, ATP: adenosine \\
\hline \multicolumn{2}{|l|}{3} & clic guanosine monophosphate, NO: nitric oxide, PAF: platelet \\
\hline \multicolumn{2}{|l|}{4} & able angina pectoris, TXA2: thromboxane A2, 8-iso-PGF2a: 8-iso- \\
\hline \multicolumn{2}{|c|}{5 prostaglandin F2 alpha. } & \\
\hline 6 & & \\
\hline
\end{tabular}




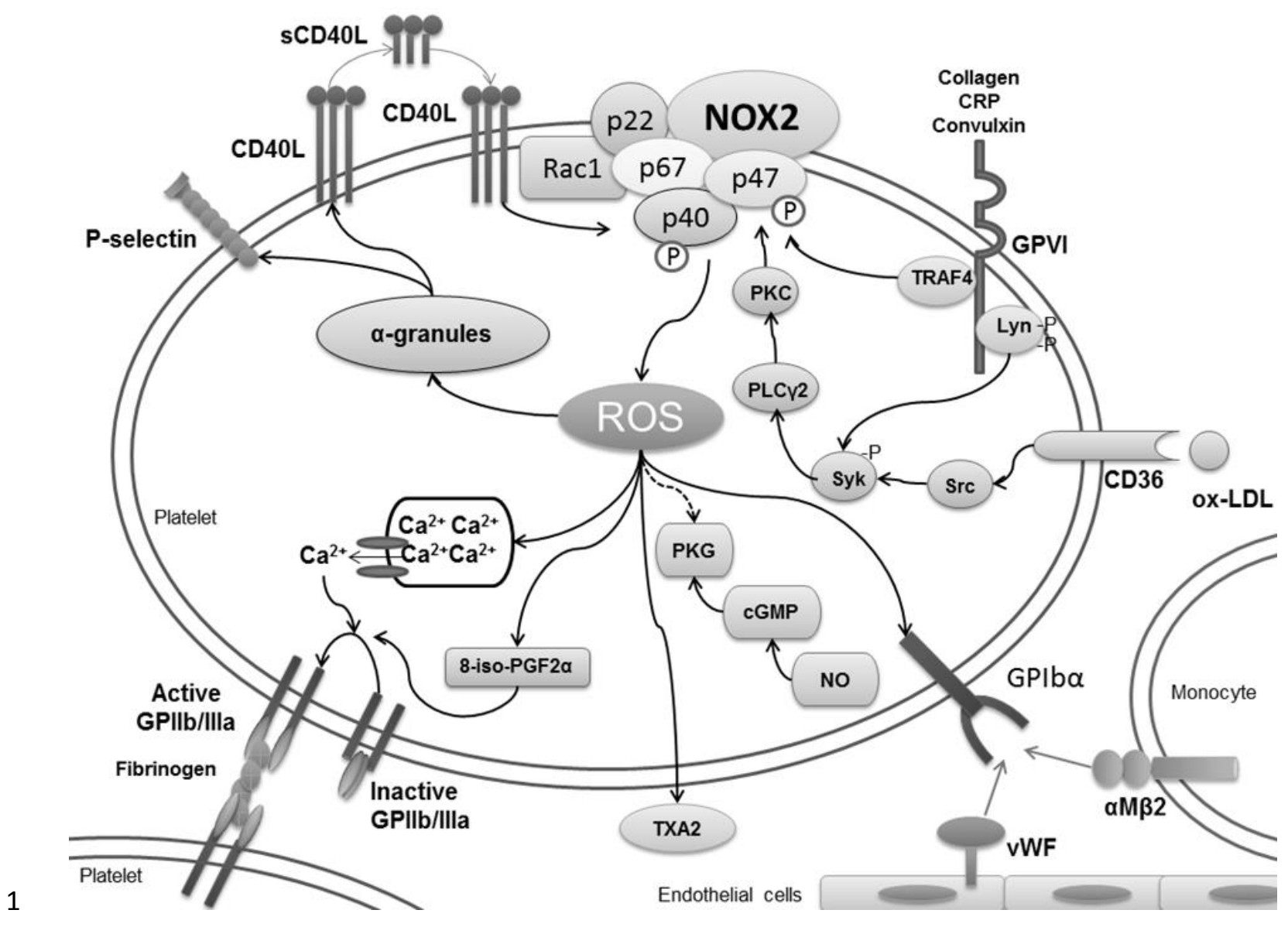

2 Figure 1. Activation and downstream signaling pathways of platelet NOX2.

3 Continuous lines: activation and dotted line: inhibition. 